\title{
ESTRANGEIROS NO BRASIL: REALIDADES E DESAFIOS
}

Marcia Sprandel $^{1}$

\begin{abstract}
Resumo:
O artigo faz um balanço da situação atual dos estrangeiros no Brasil, a partir de quatro aspectos. No que se refere a legislação, retrata o atual momento, de discussão pública de uma nova Lei de Estrangeiros; Em termos de números, analisa os dados dos Censo de 2000, além de outras fontes disponíveis sobre o tema. Procura, ainda, identificar algumas das realidades localizadas vividas por estrangeiros, especialmente aqueles em situação migratória irregular. Finalmente, defende uma nova visão do Brasil para com os estrangeiros, baseada não mais nos preceitos de segurança nacional, mas na ótica dos direitos humanos.
\end{abstract}

Palavras chaves: Estrangeiros; Migrações; Imigrantes;

\begin{abstract}
"No caso de uma pessoa estranha ao país, à cidade, à raça, etc., esse elemento não-comum (...) não tem nada de individual, é meramente a condição de origem, que é ou poderia ser comum a muitos estrangeiros. Por essa razão, os estrangeiros não são realmente concebidos como indivíduos, mas como estranhos de um tipo particular: o elemento de distância não é menos geral em relação a eles que o elemento de proximidade". (George Simmel, em "O Estrangeiro", escrito em 1908)
\end{abstract}

Entre os principais aspectos da questão envolvendo a situação de estrangeiros no Brasil estão a legislação vigente e propostas de alteração; o número de estrangeiros no Brasil (censo 2000, dados da Polícia Federal, estimativas de ilegais); os grupos mais vulneráveis; os direitos humanos dos estrangeiros e a necessidade de políticas públicas para sua proteção.

\section{Legislação vigente e propostas de alteração}

\footnotetext{
${ }^{1}$ Historiadora e antropóloga, integrante do GT de Migrações Internacionais da Comissão Nacional de População e Desenvolvimento, da Comissão de Relações Étnicas e Raciais da Associação Brasileira de Antropologia e do Grupo de Pesquisa Pensamento Social.
} 
A lei de estrangeiros em vigência no Brasil é a Lei no. 6.815, de 19 de agosto de 1980, que "define a situação jurídica do estrangeiro no Brasil cria o Conselho Nacional de Imigração e dá outras providências", enviada pelo General João Batista Figueiredo ao Congresso em regime de urgência e aprovada por decurso de prazo, menos de três meses depois.

Para alterar esta legislação, tramitou no Congresso Nacional, de 1991 a 2003, o Projeto de Lei no. 1.813/91, que "define a situação jurídica do estrangeiro no Brasil”, de autoria do Poder Executivo. Seu texto legal não agradou às associações de imigrantes nem às entidades confessionais que as representam. Recebeu dezenas de emendas e acabou sendo arquivada em dezembro de 2003.

No atual governo, criou-se no Ministério da Justiça um grupo de trabalho destinado a elaborar uma nova Lei de Estrangeiros. Antes mesmo de sua instalação, o Serviço de Proteção aos Migrantes apresentou, entre outras, as seguintes contribuições:

- Uma nova Lei dos Estrangeiros deverá estar em sintonia com os princípios da Constituição, com os princípios da Convenção Internacional sobre a Proteção dos Direitos de Todos os Trabalhadores Migrantes e dos Membros das suas Famílias (1990), os Acordos do Mercosul e o Plano Nacional de Direitos Humanos (1996).

- A questão imigratória deve ser examinada como um projeto social, econômico, cultural, de direitos humanos, pois existe uma carência de políticas que favoreçam a integração dos migrantes.

- O valor das taxas pelos serviços prestados, referentes aos documentos de imigrante, não deve ultrapassar os $10 \%$ do salário mínimo vigente no país.

- A nova lei deve prever a autorização de visto temporário ao imigrante que consiga qualquer tipo de trabalho lícito, não beneficiando apenas categorias seletivas.

- A nova lei deve garantir o direito de crianças e adolescentes indocumentados poderem estudar em escolas públicas e particulares com o direito ao recebimento de histórico escolar, certificado de conclusão de curso ou outra documentação.

Durante a audiência pública para discutir a proposta de elaboração do novo Estatuto do Estrangeiro, realizada na Subcomissão Temporária de Turismo do Senado Federal, em 
25 de novembro de $2004^{2}$, o secretário-executivo do ministério, Luiz Paulo Barreto, informou que o projeto deverá modificar totalmente a legislação que trata da imigração no Brasil, facilitando a entrada de estrangeiros em no país. O secretário lembrou, também, que a lei de refugiados brasileira é considerada modelo em todo o mundo, e que a expectativa do governo é de que o Estatuto do Estrangeiro também alcance este status.

$\mathrm{Na}$ mesma reunião, o presidente da Associação dos Juízes Federais do Brasil (Ajufe), Jorge Antonio Maurique sugeriu que a legislação leve em conta a situação de fragilidade do estrangeiro e afirmou que o estatuto deve proteger os direitos humanos, respeitando a liberdade individual e evitando discriminação de qualquer espécie.

O anteprojeto de lei foi colocado em consulta pública no dia 1 de setembro de 2005 , no sítio do Ministério da Justiça, e as entidades ou qualquer cidadão tem um prazo de trinta dias para enviar críticas e sugestões.

Numa avaliação inicial, pode-se perceber que a proposta amplia a quantidade de vistos, para a admissão de categorias como consultores técnicos, cientistas, professores, investidores, empresários, voluntários de Organizações Não-Governamentais, aposentados, estudantes, assistentes técnicos, tripulantes marítimos, prestadores de serviço, cujos casos são atualmente avaliados e atendidos por resoluções do Conselho Nacional de Imigração.

A proposta, em geral, busca resguardar os direitos civis e fundamentais do imigrante previstos na Constituição de 1988; assegurar tratamento diferenciado aos imigrantes sulamericanos, buscando a integração econômica, política, social e cultural dos povos da América Latina, e facilitar a emissão de vistos e documentos. Também prevê critérios mais claros e ágeis para a deportação ou expulsão de estrangeiros que cometerem crime no Brasil.

Incorpora as resoluções da Convenção de Palermo, no que se refere à punição ao tráfico de migrantes e seres humanos e propõe a transformação do Conselho Nacional de Imigração em Conselho Nacional de Migração, que - com uma nova composição e localização na estrutura governamental- incorpore também, entre suas atribuições, a formulação de políticas públicas para emigrantes brasileiros.

\footnotetext{
${ }^{2}$ Jornal do Senado/Edição de quinta-feira, 25 de novembro de 2004. "Estatuto poderá facilitar entrada de estrangeiros". "Estudo do Ministério da Justiça modificará totalmente a legislação que trata da imigração no Brasil".
} 
Temos pela frente um período de intensos debates, até que seja acordada a versão que deverá ser enviada ao Congresso pelo Executivo Federal. No Congresso, pode-se prever ainda alguns anos de discussão, dada a relevância do tema e a abertura que o anteprojeto dá à questão dos brasileiros no exterior, o que poderá ensejar aos parlamentares (principalmente aqueles envolvidos na Comissão Parlamentar de Inquérito da Emigração Ilegal) uma oportunidade para transforma-lo numa espécie de "lei geral de migrações", nos moldes da legislação argentina.

Vale lembrar que, no primeiro semestre de 2005, tramitavam no Congresso Nacional, 17 (dezessete) matérias referentes ao tema "estrangeiros" (ver anexo 1), o que, somado às matérias sobre brasileiros no exterior, demonstra o quanto o parlamente está envolvido no compromisso de mudar as leis imigratórias vigentes e propor leis de emigração.

Existem, ainda, importantes Decretos Legislativos já aprovados, pelo Parlamento, conforme listados abaixo:

SF PDS 761/2003 de 14/10/2003. Ementa: Aprova o texto do Acordo sobre Isenção de Vistos entre os Estados Partes do Mercosul, concluído em Florianópolis, em 15 de dezembro de 2000. Norma jurídica gerada: DLG-000971 de 2003

SF PDS 858/2003 de 06/11/2003 Ementa: Aprova o texto do Acordo sobre Dispensa de Tradução de Documentos Administrativos para Efeitos de Imigração entre os Estados Partes do Mercosul, a República da Bolívia e a República do Chile, celebrado em Florianópolis, em 15 de dezembro de 2000. Norma jurídica gerada: DLG-000198 de 2004

SF PDS 943/2003 de 28/11/2003Ementa: Aprova o texto do Acordo sobre Residência para Nacionais dos Estados Partes do MERCOSUL, celebrado por ocasião da XXIII Reunião do Conselho do Mercosul Comum, realizada em Brasília, nos dias 5 e 6 de dezembro de 2002.Norma jurídica gerada: DLG-000210 de 2004

SF PDS 134/2005 de 21/03/2005 Ementa: Aprova o texto do Acordo, por Troca de Notas, de Vistos Gratuitos aos Estudantes e Docentes, entre o Governo da República Federativa do Brasil e o Governo da República Argentina, celebrado em Buenos Aires, em 14 de agosto de 2001. Norma jurídica gerada: DLG000785 de 2005

SF PDS 346/2005 de 21/07/2005Ementa: Aprova o texto do Acordo entre o Governo da República Federativa do Brasil e o Governo da República do Peru sobre Facilitação para o Ingresso e Trânsito de seus Nacionais em seus Territórios, celebrado em Lima, em 10 de fevereiro de 2004. Norma jurídica gerada: DLG-000883 de 2005

SF PDS 347/2005 de 21/07/2005 Ementa: Aprova o texto do Acordo entre o Governo da República Federativa do Brasil e o Governo da República da Bolívia sobre Facilitação para o Ingresso e Trânsito de seus Nacionais em seus Territórios, celebrado em Santa Cruz da Serra, em 8 de julho de 2004. Norma jurídica gerada: DLG-000884 de 2005

SF PDS 353/2005 de 21/07/2005 Ementa: Aprova o texto do Acordo sobre Regularização Migratória Interna de Cidadãos do Mercosul, Bolívia e Chile, celebrado por ocasião da XXIII Reunião do Conselho do Mercado Comum, realizada em Brasília, nos dias 5 e 6 de dezembro de 2002.

SF PDS 354/2005 de 21/07/2005Ementa: Aprova o tex to do Protocolo de Integração Educacional para a Formação de Recursos Humanos no Nível de Pós-Graduação entre os Estados Partes do Mercosul e da República da Bolívia, assinado em Brasília, em 05 de dezembro de 2002.

SF PDS 355/2005 de 21/07/2005 Ementa: Aprova o texto do Acordo sobre Residência para Nacionais dos 
Estados Partes do Mercado Comum do Sul - Mercosul, Bolívia e Chile, celebrado por ocasião da XXIII Reunião do Conselho do Mercado Comum, realizada em Brasília, nos dias 5 e 6 de dezembro de 2002. SF PDS 365/2005 de 21/07/2005Ementa: Aprova o texto do Acordo sobre Regularização Migratória Interna de Cidadãos do Mercosul, celebrado por ocasião da XXIII Reunião do Conselho do Mercado Comum, realizada em Brasília, nos dias 5 e 6 de dezembro de 2002.

SF PDS 366/2005 de 21/07/2005 Ementa: Aprova o texto do Acordo sobre Concessão de Vistos de Múltiplas Entradas para Determinadas Categorias de Pessoas, assinado em Brasília, em 30 de julho de 2002, por ocasião da IV Conferência de Chefes de Estado e de Governo da Comunidade dos Países de Língua Portuguesa - CPLP.

SF PDS 367/2005 de 21/07/2005 Ementa: Aprova o texto do Acordo sobre Dispensa de Tradução para Documentos Administrativos para Efeitos de Imigração entre os Estados Partes do Mercosul, celebrado em Florianópolis, em 15 de dezembro de 2000.

SF PDS 363/2005 de 21/07/2005 Ementa: Aprova o texto do Acordo entre o Governo da República Federativa do Brasil e o Governo da República da Guiana sobre Isenção Parcial de Vistos, celebrado em Brasília, em 30 de julho de 2003.

SF PDS 370/2005 de 21/07/2005 Ementa: Aprova o texto do Acordo sobre Isenção de Taxas e Emolumentos Devidos à Emissão e Renovação de Autorizações de Residências para os Cidadãos da Comunidade dos Países de Língua Portuguesa, assinado em Brasília, em 30 de julho de 2002

O Governo Brasileiro, por sua vez, tem promulgado decretos importantes sobre o assunto:

Decreto no. 5.105, de 14.6.2004, publicado no Diário Oficial da União (DOU) de 15.6.2004, que Promulga o Acordo entre o Governo da República Federativa do Brasil e o Governo da República Oriental do Uruguai para Permissão de Residência, Estudo e Trabalho a Nacionais Fronteiriços Brasileiros e Uruguaios, de 21 de agosto de 2002

Decreto no. 5.017, de 12.3.2004, publicado no DOU de 15.3.2004, que Promulga o Protocolo Adicional à Convenção das Nações Unidas contra o Crime Organizado Transnacional Relativo à Prevenção, Repressão e Punição do Tráfico de Pessoas, em Especial Mulheres e Crianças

Decreto no. 5.016, de 12.3.2004, publicado no DOU de 15.3.2004, que Promulga o Protocolo Adicional à Convenção das Nações Unidas contra o Crime Organizado Transnacional, relativo ao Combate ao Tráfico de Migrantes por Via Terrestre, Marítima e Aérea

Decreto no. 4.975, de 30.1.2004, Publicado no DOU de 2.2.2004, que Promulga o Acordo de Extradição entre os Estados Partes do Mercosul

Decreto no. 4.921, de 17.12.2003 , publicado no DOU de 18.12.2003, que Promulga o Convênio entre o Governo da República Federativa do Brasil e o Governo da República Argentina sobre Assistência aos Nacionais de cada uma das Partes que se Encontrem em Território de Estados nos quais não haja Representação Diplomática ou Consular de seus Respectivos Países, de 14 de agosto de 2001

Destes, destaca-se o “Acordo sobre Residência para Nacionais dos Estados Partes do MERCOSUL”, que prevê que os cidadãos de quaisquer países do Mercosul, natos ou naturalizados há pelo menos cinco anos, terão um processo simplificado na obtenção de residência temporária por até dois anos em outro país do bloco, tendo como exigências o passaporte válido, certidão de nascimento, certidão negativa de antecedentes penais e, dependendo do país, certificado médico de autoridade migratória (art. $4^{\circ}$ ).

O Acordo prevê, também, que a residência temporária, no decurso do prazo, pode se transformar em residência permanente com a mera comprovação de meios de vida lícitos 
para o sustento próprio e familiar (art. $5^{\circ}$ ). Além das liberdades civis - direito de ir e vir, ao trabalho, à associação, ao culto e outros - $\left(\operatorname{art.} 9^{\circ}, 1\right)$, do direito de reunião familiar (art. $9^{\circ}$, 2) e de transferência de recursos (art. $9^{\circ}, 5$ ), o Acordo faz avanços em duas áreas importantes: a trabalhista e a educacional.

No caso dos direitos trabalhistas, existe uma clara definição no $\operatorname{art.~}^{\circ}, 3$, de igualdade na aplicação da legislação trabalhista, além do compromisso de acordos de reciprocidade em legislação previdenciária. A migração forçada trará conseqüências aos empregadores, mas não afetará os direitos dos trabalhadores migrantes (art. 10).A relação educacional dos filhos dos imigrantes os insere em igualdade de condições com os nacionais do país de recepção. Além do que, o Artigo 11 prevê que, na dúvida legislativa, a resposta interpretativa deve ser sempre pró-migrante:

\section{Número de estrangeiros no Brasil}

Durante os anos 90, o Brasil recebeu número significativo de imigrantes (legais e ilegais) da Coréia do Sul e de países da América Latina, especialmente Bolívia e Peru. Vejamos, a seguir, os dados do censo de 2000, analisados por Amaral e Fusco (2005):

Censo 2000 (fluxo internacional para o Brasil entre 1990 e 2000)

- $46.5 \%$ (ou 43,125 pessoas) provenientes da América Central e do Sul;

- 23,4\% (ou 21,636 pessoas) da Europa;

- $15,5 \%$ (14.368) da Ásia e

- $9,7 \%(9,029)$ da América do Norte.

Censo de 2000- número de estrangeiros, por país de nascimento.

- 385,194 (56.3\%) vieram da Europa,

- 143,274 (21\% das Américas do Sul e Central)e

- $\mathbf{1 2 1 , 7 8 7}$ (17.8\% da Ásia).

- As maiores populações : Portugal (31.2\%), Japão (10.4\%) e Itália (8 \%).

- Censo 2000- imigrantes por UF de residência 
- A região Sudeste era o destino principal dos imigrantes, recebendo $73,4 \%$ da população total de imigrantes, que era da 683.830 .

- Quase metade deste total (343.944) estava no estado de São Paulo.

- Outros estados com números altos de imigrantes eram Rio de Janeiro, Paraná, Minas Gerais e Rio Grande do Sul.

Sistema Nacional de Cadastramento e Registro de Estrangeiros -SINCRE (fev/2005) Totais de estrangeiros residentes no Brasil por nacionalidade (mais de 10.000)

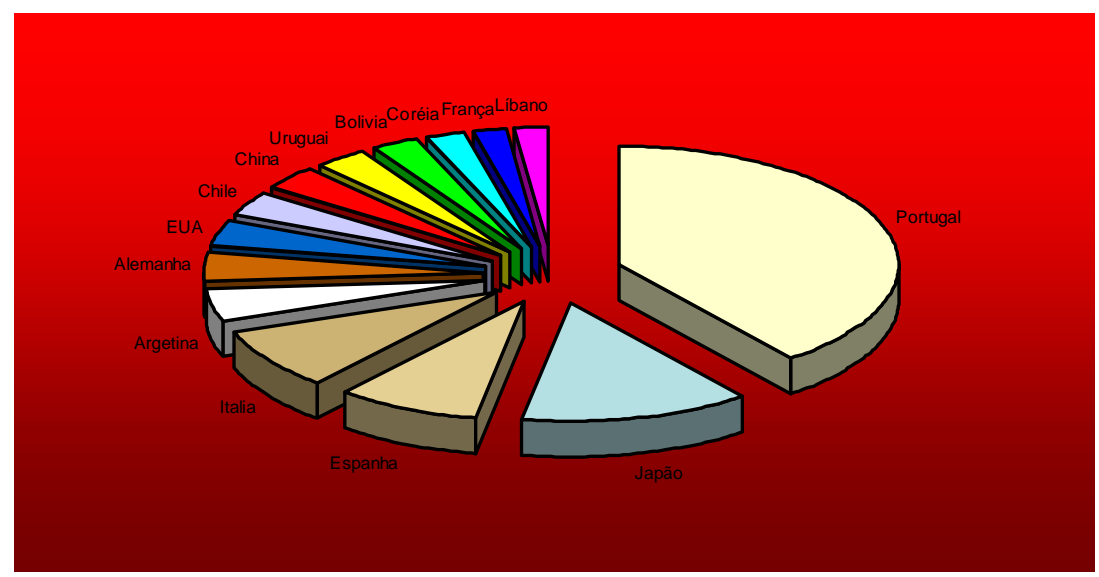

\subsection{7 estrangeiros com registro ativo.}

- $33,5 \%$ (278.125) portugueses;

- $11,4 \%$ (94.980) japoneses;

- $7 \%$ (58.510) espanhóis;

- $6,4 \%(58.313)$ italianos;

- $3,9 \%$ (32.606) argentinos;

- $3,2 \%$ (26.966) alemães;

- $3 \%$ (25.087) norte-americanos;

- $2,9 \%(24.834)$ chilenos;

- $2,7 \%$ (22.991) chineses;

- $2,7 \%$ (22.478 uruguaios);

- $2,2 \%$ (19.064) bolivianos; 
- $1,8 \%(15.496)$ coreanos;

- $1,6 \%$ (13.666) franceses e

- $(1,6 \%) 13.594$ libaneses.

$\underline{\text { SINCRE (FEV.2005) - No. de estrangeiros com registro ativo, por UF }}$

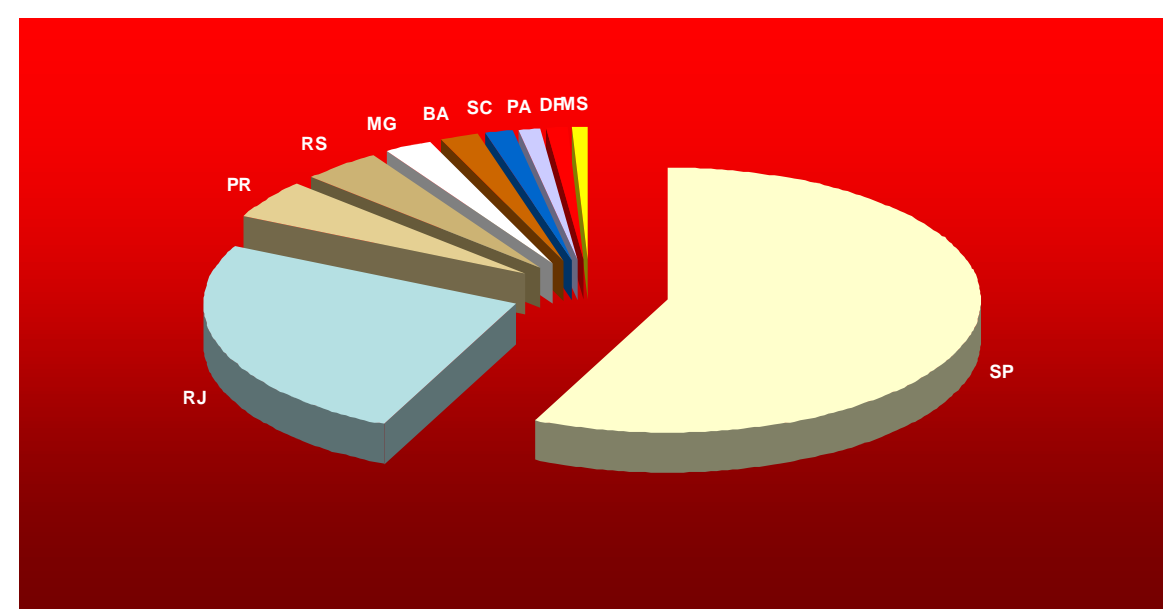

Os dez estados com maior registro de população estrangeira são:

- São Paulo, com 54\% do total (448.563);

- Rio de Janeiro, com $23 \%$ (198.385);

- Paraná, com 4,6\% (38.630);

- Rio Grande do Sul, com 3,9\% (33,127);

- Minas Gerais, com 2,4\% (20.101);

- Bahia, com 1,6\% (13.753);

- Santa Catarina, com 1,4\% (12.289);

- Pará (8.092);

- Distrito Federal (7.915) com 0,9\% e

- Mato Grosso do Sul, com 0,8\% (7.290).

\section{Os grupos mais vulneráveis}


Em 1998, a Polícia Federal calculava que viviam no país cerca de 100 mil estrangeiros em situação irregular: bolivianos, chineses, coreanos, argentinos, chilenos, uruguaios, libaneses, peruanos e angolanos. Hoje, esse número é muito maior. A Folha de São Paulo de 20/03/2005, numa estimativa que me parece exagerada, afirma que "Brasil tem mais de 1,5 milhão de imigrantes irregulares". Das safras migratórias mais recentes, $80 \%$ seriam bolivianos, seguidos de peruanos, chineses e africanos.

Conforme o jornal "La Nación", de 27/01/05, os imigrantes argentinos ilegais no Brasil seriam mais de 100 mil, espalhados principalmente entre Florianópolis, Camboriú, Búzios e São Paulo.

A Comissão Parlamentar de Inquérito que investiga a exploração de mão-de-obra boliviana em São Paulo, trabalha com um número de 40 mil, com base nos dados do Consulado da Bolívia e dos ministérios da Justiça e Trabalho. O Sindicato das Costureiras estima em 70 mil este número.

Ou seja, os números são imprecisos e demonstram, sobretudo, a fragilidade da situação do estrangeiro ilegal, que leva a uma invisibilidade potencialmente geradora de abusos e desrespeitos aos direitos humanos fundamentais de qualquer trabalhador migrante.

Uma fonte importante de informações sobre os estrangeiros em situação migratória irregular é a mídia impressa. A partir de um levantamento deste material, feito na lista de discussões do Núcleo Interdisciplinar de Estudos Migratórios (NIEM), da Universidade do Estado do Rio de Janeiro, no período de janeiro a julho de 2005, pudemos elaborar o quadro abaixo, demonstrativo de algumas das situações localizadas envolvendo estrangeiros no Brasil: 
Estrangeiros no Brasil $^{3}$

\begin{tabular}{|c|c|c|c|c|c|c|c|}
\hline País de origem & Lead da matéria & $\begin{array}{l}\text { Informação sobre } \\
\text { quantidade }\end{array}$ & $\begin{array}{l}\text { Informação sobre } \\
\text { localização }\end{array}$ & $\begin{array}{l}\text { informação sobre } \\
\text { ocupação }\end{array}$ & $\begin{array}{l}\text { Autoridades ou } \\
\text { entidades citadas }\end{array}$ & $\begin{array}{l}\text { Envolvimento com } \\
\text { ilicitude }\end{array}$ & Fonte \\
\hline América Latina & $\begin{array}{l}\text { Migrantes latinos } \\
\text { também são } \\
\text { explorados }\end{array}$ & & São Paulo & & & $\begin{array}{l}\text { Trabalho Ilegal, } \\
\text { Imigração Ilegal }\end{array}$ & Folha de São Paulo, 19/7/04 \\
\hline China & $\begin{array}{l}\text { Chineses são presos } \\
\text { em SP por extorsão }\end{array}$ & 2 & São Paulo & & Polícia & Extorsão & Folha de São Paulo, 20/7/04 \\
\hline Cabo Verde & $\begin{array}{l}\text { Camelôs cruzam } \\
\text { Atlântico para } \\
\text { comprar em SP }\end{array}$ & & São Paulo & $\begin{array}{l}\text { Camelôs fazem } \\
\text { compra em SP }\end{array}$ & & & Folha de São Paulo, 25/7/04 \\
\hline Bolívia & \begin{tabular}{|l|} 
Feiras nos finais de \\
semana, bairro de \\
Canindé vira La Paz
\end{tabular} & $\begin{array}{l}50 \text { mil imigrantes } \\
\text { legais, previsão do } \\
\text { mesmo no. de } \\
\text { ilegais }\end{array}$ & São Paulo & & & Imigração Ilegal & Folha de São Paulo, 9/5/04 \\
\hline Árabes & $\begin{array}{l}\text { Arabs Love Brazil. } \\
\text { They Are } 7 \% \text { of the } \\
\text { Country } \\
\end{array}$ & & & Imigração & & & $\begin{array}{l}\text { Brazil - Immigration - } \\
\text { September } 2004\end{array}$ \\
\hline \multirow[t]{2}{*}{ Angola } & $\begin{array}{l}\text { UFJF recebe } \\
\text { exilados angolanos }\end{array}$ & 3 & & $\begin{array}{l}\text { Alunos angolanos } \\
\text { exilados estudam na } \\
\text { UFJF }\end{array}$ & & & $\begin{array}{l}\text { Publicado no Espaço } \\
\text { Universitário do site do Banco } \\
\text { Real em 21/09/2004 }\end{array}$ \\
\hline & \begin{tabular}{|l|} 
Executivo \\
estrangeiro cria rede \\
de proteção \\
\end{tabular} & & & Imigrantes legais & $\begin{array}{l}\text { Ministério do } \\
\text { Trabalho e Emprego }\end{array}$ & & Folha de São Paulo, 12/9/04 \\
\hline Cuba & \begin{tabular}{|l|} 
Basquete tira da \\
sombra a primeira \\
atleta refugiada \\
\end{tabular} & 1 & Americana, SP & & & & Folha de São Paulo, 2/9/04 \\
\hline $\begin{array}{l}\text { Bolívia, Paraguai e } \\
\text { Peru }\end{array}$ & $\begin{array}{l}\text { Procuradoria flagra } \\
\text { trabalho escravo em } \\
\text { SP }\end{array}$ & 11 & São Paulo & $\begin{array}{l}\text { Trabalhadores } \\
\text { bolivianos, } \\
\text { paraguaios e } \\
\text { peruanos }\end{array}$ & & Trabalho escravo & Folha de São Paulo, 21/8/04 \\
\hline China & $\begin{array}{l}\text { Chineses em São } \\
\text { Paulo }\end{array}$ & & & & & Imigrantes Ilegais & Folha de São Paulo \\
\hline Afegãos & $\begin{array}{l}\text { A vida dos afegãos } \\
\text { três anos depois }\end{array}$ & 23 & Porto Alegre & & ONU & & Zero Hora, 25/04/05 \\
\hline
\end{tabular}

3 


\begin{tabular}{|c|c|c|c|c|c|c|c|}
\hline Tríplice Fronteira & $\begin{array}{l}\text { Diversidad cultural, } \\
\text { inmigración y } \\
\text { discriminación }\end{array}$ & & & $\begin{array}{l}\text { Artigo sobre a } \\
\text { tríplice fronteira }\end{array}$ & & & Argenpress, abril 2005 \\
\hline EUA & $\begin{array}{l}\text { Polícia Federal } \\
\text { detém no Rio } \\
\text { estrangeiros que } \\
\text { estavam em barco } \\
\text { com } 40 \text { mulheres }\end{array}$ & 29 & Rio de Janeiro & & $\mathrm{PF}$ & \begin{tabular}{|l} 
Detenção por \\
Turismo Sexual
\end{tabular} & $12 / 06 / 2005$ \\
\hline Espanha & $\begin{array}{l}\text { PF prende grupo de } \\
\text { Goiás acusado de } \\
\text { tráfico de mulheres }\end{array}$ & 7 pessoas & & $\begin{array}{l}\text { Policial Federal é } \\
\text { acusado }\end{array}$ & $\mathrm{PF}$ & \begin{tabular}{|l|} 
Tráfico de mulheres, \\
imigração ilegal
\end{tabular} & Folha de São Paulo, 4/12/04 \\
\hline EUA & $\begin{array}{l}\text { PF prende } 5 \text { cubanos } \\
\text { e } 1 \text { brasileiro em } \\
\text { operação contra } \\
\text { tráfico de pessoas }\end{array}$ & 6 pessoas & & & $\mathrm{PF}$ & Imigração Ilegal & Folha de São Paulo, 11/12/04 \\
\hline EUA & $\begin{array}{l}\text { Prefeito eleito tem } \\
\text { esquema de } \\
\text { imigração }\end{array}$ & & & & & Imigração Ilegal & Folha de São Paulo, 26/12/04 \\
\hline EUA & $\begin{array}{l}\text { Parceria contra o } \\
\text { comércio de } \\
\text { escravos }\end{array}$ & & & & & \begin{tabular}{|l|} 
Tráfico de seres \\
humanos
\end{tabular} & Folha de São Paulo, 06/01/05 \\
\hline Argentina & $\begin{array}{l}\text { No deportan a } \\
\text { argentinos ilegales }\end{array}$ & $\begin{array}{l}100.000 \text { números } \\
\text { não oficiais }\end{array}$ & São Paulo & $\begin{array}{l}\text { Regularização de } \\
\text { imigrantes, } \\
\text { trabalhadores ilegais }\end{array}$ & Ministério da Justiça & Imigração Ilegal & $\begin{array}{l}\text { La Nación (Buenos Aires), } \\
27 / 01 / 05\end{array}$ \\
\hline Bolivia & $\begin{array}{l}\text { Bolivia y Brasil } \\
\text { elaboran convenio } \\
\text { para favorecer a } \\
\text { inmigrantes }\end{array}$ & $\begin{array}{l}\text { Vários milhares, } \\
\text { números não oficiais }\end{array}$ & São Paulo & $\begin{array}{l}\text { Regularização de } \\
\text { imigrantes, } \\
\text { trabalhadores ilegais }\end{array}$ & Ministério da Justiça & Imigração Ilegal & UniVision, 16/02/05 \\
\hline Paraguai & $\begin{array}{l}\text { Índios paraguaios } \\
\text { buscam auxílio em } \\
\text { Mato Grosso do Sul }\end{array}$ & $\begin{array}{l}1.500 \text { números não } \\
\text { oficiais }\end{array}$ & $\begin{array}{l}\text { Japorã e Iguatemi, } \\
\text { MS }\end{array}$ & $\begin{array}{l}\text { Busca de } \\
\text { atendimento médico }\end{array}$ & $\begin{array}{l}\text { FUNASA, } \\
\text { Consulado do } \\
\text { Paraguai em Campo } \\
\text { Grande, Itaipu } \\
\text { BINACIONAL }\end{array}$ & Imigração Ilegal & Folha de São Paulo, 08/03/05 \\
\hline África & $\begin{array}{l}\text { Refugiados } \\
\text { africanos vão } \\
\text { estudar na UFF }\end{array}$ & & Niterói & $\begin{array}{l}\text { Refugiados prestam } \\
\text { vestibular }\end{array}$ & $\begin{array}{l}\text { UFF, ARAB } \\
\text { (Associação dos } \\
\text { Refugiados } \\
\text { Africanos no Brasil }\end{array}$ & & $\begin{array}{l}\text { 01/02/05, notícia enviada por } \\
\text { Felipe Asensi e Adriana } \\
\text { Marcolini }\end{array}$ \\
\hline Uruguai/ Argentina & $\begin{array}{l}\text { Represor Uruguayo } \\
\text { pide refúgio en } \\
\text { Brasil }\end{array}$ & 1 & Porto Alegre & $\begin{array}{l}\text { Pedido de refúgio } \\
\text { para coronel } \\
\text { uruguaio acusado de } \\
\text { violar direitos }\end{array}$ & $\mathrm{PF}$ & $\begin{array}{l}\text { ordem de captura } \\
\text { internacional }\end{array}$ & Ansalatina.com, 16/02/05: \\
\hline
\end{tabular}




\begin{tabular}{|c|c|c|c|c|c|c|c|}
\hline & & & & humanos & & & \\
\hline Uruguai/ Argentina & $\begin{array}{l}\text { Caso Cordero chega } \\
\text { ao Itamaraty }\end{array}$ & 1 & $\begin{array}{l}\text { Santana do } \\
\text { Livramento }\end{array}$ & $\begin{array}{l}\text { Pedido de refúgio } \\
\text { para coronel } \\
\text { uruguaio acusado de } \\
\text { violar direitos } \\
\text { humanos }\end{array}$ & $\begin{array}{l}\text { Itamaraty, } \\
\text { Ministério da } \\
\text { Justiça, Interpol }\end{array}$ & $\begin{array}{l}\text { ordem de captura } \\
\text { internacional }\end{array}$ & Zero Hora, 17/02/05 \\
\hline Uruguai/ Argentina & $\begin{array}{l}\text { Uruguaios vão } \\
\text { protestar }\end{array}$ & 1 & Porto Alegre & $\begin{array}{l}\text { Pedido de refúgio } \\
\text { para coronel } \\
\text { uruguaio acusado de } \\
\text { violar direitos } \\
\text { humanos }\end{array}$ & & & Jornal Zero Hora, 17/02/2005 \\
\hline Uruguai/ Argentina & $\begin{array}{l}\text { Militar uruguaio } \\
\text { pede refúgio ao } \\
\text { Brasil }\end{array}$ & 1 & & $\begin{array}{l}\text { Pedido de refúgio } \\
\text { para coronel } \\
\text { uruguaio acusado de } \\
\text { violar direitos } \\
\text { humanos }\end{array}$ & $\begin{array}{l}\text { Itamaraty, } \\
\text { Ministério da } \\
\text { Justiça, Interpol, } \\
\text { STF }\end{array}$ & $\begin{array}{l}\text { Tortura, violação de } \\
\text { direitos humanos }\end{array}$ & Folha de São Paulo, 04/03/05 \\
\hline Uruguai/ Argentina & $\begin{array}{l}\text { País deve julgar ou } \\
\text { extraditar coronel, } \\
\text { diz advogado }\end{array}$ & 1 & & $\begin{array}{l}\text { Pedido de refúgio } \\
\text { para coronel } \\
\text { uruguaio acusado de } \\
\text { violar direitos } \\
\text { humanos }\end{array}$ & & $\begin{array}{l}\text { Tortura, Violação } \\
\text { dos Direitos } \\
\text { Humanos }\end{array}$ & Folha de São Paulo, 04/03/05 \\
\hline \multirow[t]{2}{*}{ Coréia } & $\begin{array}{l}\text { Imigração coreana } \\
\text { transforma bairro de } \\
\text { SP }\end{array}$ & & São Paulo & Imigração Coreana & & & Folha de São Paulo, 13/02/05 \\
\hline & $\begin{array}{l}\text { Brasil tem 1,5 } \\
\text { milhão de } \\
\text { imigrantes } \\
\text { irregulares }\end{array}$ & $\begin{array}{l}5.000 \text { estrangeiros } \\
\text { ilegais }\end{array}$ & São Paulo & $\begin{array}{l}\text { Total de } 1,5 \text { milhão } \\
\text { de estrangeiros } \\
\text { ilegais }\end{array}$ & & Imigração Ilegal & Folha de São Paulo, 20/03/05 \\
\hline Muçulmanos & $\begin{array}{l}\text { "No tenemos nada } \\
\text { que esconder", dicen } \\
\text { islámicos de Foz de } \\
\text { Iguazú }\end{array}$ & $\begin{array}{l}\text { Entre } 12.000 \mathrm{e} \\
14.000\end{array}$ & & & & $\begin{array}{l}\text { Combate ao } \\
\text { terrorismo }\end{array}$ & $\begin{array}{l}\text { Misiones Online (Argentina), } \\
\text { 14/03/05 }\end{array}$ \\
\hline
\end{tabular}

Quadro elaborado pelo antropólogo José Gabriel Silveira Corrêa (Museu Nacional/UFRJ) 


\section{Os direitos humanos dos estrangeiros}

A Convenção Internacional sobre a Proteção dos Direitos de Todos os Trabalhadores Migrantes e dos Membros das suas Famílias (1990) é, hoje, uma garantia na proteção jurídica aos migrantes, reconhecendo e protegendo sua dignidade como seres humanos, independentemente de sua condição legal.

A Convenção já entrou em vigor, graças à ratificação por mais de 20 países. Todavia, o documento segue vinculando somente países que dela são signatários. É fundamental a articulação nacional pela assinatura da Convenção pelo Governo Brasileiro, conforme já está previsto no Plano Nacional de Direitos Humanos (1996).

\section{Políticas Públicas para as Migrações Internacionais}

Pode-se dizer que, no Brasil contemporâneo, não existem ainda políticas públicas de migração. Documento recente, produzido para o Parlatino e para a Confederação Parlamentar das Américas (Copa) pelo Dep. Orlando Fantazzini e técnicos e especialistas em direitos humanos, traz uma série de propostas para formulação destas políticas, a partir de enfoques como o impacto da economia globalizada sobre as migrações internacionais; migrações e os instrumentos internacionais de direitos humanos; conceito de migrantes, refugiados e asilados; os migrantes e a cidadania política; políticas para as embaixadas e consulados; políticas públicas para apoio aos migrantes e seus familiares;remessas financeiras dos cidadãos residentes no exterior; capacitação dos agentes públicos e políticos que trabalham com migrantes e refugiados; estrangeiros em custódia e detidos em prisão; campanhas de opinião pública; o papel do parlamento e o tráfico internacional de pessoas.

Trata-se de documento fundamental para a elaboração de leis e de políticas públicas para estrangeiros no Brasil e brasileiros no exterior. Uma das integrantes da equipe que participou da redação do documento, Rosita Milesi, resume o espírito da sociedade civil em relação ao assunto:

“A inserção do Brasil no cenário internacional não pode prescindir de uma abertura, acolhida e proteção dos imigrantes e refugiados no âmbito de suas 
fronteiras, assim como, com a mesma sensibilidade, proteger, amparar e lutar pela defesa dos direitos de seus nacionais emigrados. Toda a pessoa é portadora de uma cidadania universal, configurada no conjunto de direitos inalienáveis próprios da condição de ser humano, que ninguém tem o direito de violar ou subestimar." (Rosita Milesi) ${ }^{4}$

O Brasil precisa assumir, de vez, sua nova inserção no mundo contemporâneo. Vivem no exterior, conforme estimativas diversas, de 2,5 a 4 milhões de brasileiros. Se queremos que seus direitos humanos e de cidadania sejam respeitados em terra estrangeira, não pode ser outro o tratamento a ser dado aos estrangeiros em nosso país.

\section{BIBLIOGRAFIA}

Amoral, Ernesto Friedrich e Fusco, Wilson- "Shaping Brazil: The Role of International Migration". Migration Information Source, junho de 2005.

Fantazzini, Orlando- "Políticas Públicas para a Migrações Internacionais". Brasília, mimeo, janeiro de 2005.

Simmel, Georg- “O estrangeiro”. In:_ Georg Simmel:sociologia. São Paulo, Ática, 1093.

\footnotetext{
${ }^{4}$ Disponível no sitio da Agência de Informações Frei Tito para a América Latina.
} 


\section{Anexo}

Matérias sobre "estrangeiros" em tramitação no Congresso Nacional

- PL-3597/2004, de Carlos Mota - PL/MG.Ementa: Acrescenta $\S \S 1^{\circ}$ a $4^{\circ}$ ao art. 32 da Lei n ${ }^{\circ}$ 8.069, de 13 de julho de 1990. Explicação: Exigindo o comparecimento periódico do adotante e do adotado perante autoridade pública sendo que, no caso de adoção por estrangeiros, este comparecimento será no consulado mais próximo à residência do adotante.

- PL-2845/2003 Autor: Nelson Pellegrino - PT/BA e outros.Ementa: Estabelece normas para a organização e a manutenção de políticas públicas específicas de prevenção e enfrentamento ao tráfico de seres humanos, especialmente mulheres e crianças, institui o Sistema Nacional de Prevenção e Enfrentamento ao Tráfico de Seres Humanos e dispõe sobre a regulamentação de seus aspectos civis e penais. Explicação: Considerando como parte integrante deste projeto o texto da "Convenção das Nações Unidas contra o Crime Organizado Transnacional" e seus Protocolos.

- PL-2430/2003 Autor: Carlos Eduardo Cadoca-PMDB/PE. Ementa: Altera a redação do art. 10 da Lei $n^{\circ}$ 6.815, de 19 de agosto de 1980. Explicação: Dispensando o visto para entrada de turistas nacionais dos Estados Unidos da América.

- PL-2375/2003 Autor: Antonio Carlos Pannunzio - PSDB/SP.Ementa: Modifica o Decreto-Lei $n^{\circ}$ 2.848, de 07 de dezembro de 1940 - Código Penal; a Lei nº 6.815, de 19 de agosto de 1980; e a Lei $n^{\circ} 8.069$, de 13 de julho de 1990 - Estatuto da Criança e do Adolescente, para estabelecer a tipificação criminal do tráfico de pessoas, suas penalidades e outras disposições correlatas. Explicação: Incluindo na tipificação o tráfico de pessoas e crianças para fins de prostituição, trabalhos forçados, trabalho escravo, remoção e comercialização de órgão humano. 
- PL-2095/2003 Autor: Coronel Alves - PL/AP. Ementa: Altera a lei no 4.737, de 15 de julho de 1965, que institui o Código Eleitoral Explicação: Proibindo o alistamento eleitoral aos estrangeiros e conscritos que estiverem cumprindo o serviço militar obrigatório; regulando o direito do militar de elegibilidade.

- PL-283/2003 Autor: Laura Carneiro - PFL/RJ. Ementa: Dispõe sobre caso de concessão de visto permanente a estrangeiro residente no Brasil. Explicação: Concedendo visto permanente a estrangeiro que tiver sob sua responsabilidade econômica criança ou adolescente junto a entidade filantrópica, alterando a Lei 6815 de 19 de agosto de 1980.

- PL-114/2003 Autor: Iara Bernardi - PT/SP. Ementa: Dispõe sobre informação dos crimes contra os costumes a turistas estrangeiros.

- PL-7231/2002 Autor: Valdemar Costa Neto - PL/SP.Ementa: Modifica a Lei nº 6.815 de 19 de agosto de 1980, simplificando a documentação de estrangeiros no Brasil.

- PL-6153/2002 Autor: Neuton Lima. Ementa: Altera a redação da alinea b do inciso II do art. 75 da Lei n. 6.815, de 19 de agosto de 1980 Explicação: Estabelecendo que não haverá expulsão de estrangeiro quando esse tiver filho brasileiro, comprovadamente, sob sua guarda e seu dependente econômico, desde que sua concepção não tenha se dado durante o procedimento de deportação.

- PL-4969/2001 Autor: José Carlos Coutinho - PFL/RJ. Ementa: Modifica o art. 19 da Lei $\mathrm{n}^{\circ} 6.815$, de 19 de agosto de 1980, que define a situação jurídica do estrangeiro no Brasil, cria o Conselho Nacional de Imigração, e dá outras providências. Explicação: Concedendo o visto diplomático a autoridade de representação comercial de países com os quais o Brasil não mantém relações diplomáticas. 
- PL-4489/2001 Autor:Poder Executivo.Ementa: Decreta expressamente revogada a Lei $\mathbf{n}^{0}$ 2.416, de 28 de junho de 1911, e demais diplomas legais referentes a estrangeiros que especifica.

- PL-527/1999 Autor: Enio Bacci - PDT/RS.Ementa: Altera a letra "a" do inciso II do art. 75 da Lei $n^{\circ}$ 6.815, de 1980. Explicação: dispondo que não se procederá a expulsão quando o estrangeiro tiver cônjuge brasileiro ao qual não esteja separado; extinguindo a exigência de que o casamento tenha no mínimo cinco anos.

- PL-4115/1993 Autor: Jackson Pereira - PSDB/CE. Ementa: Dispõe sobre o ingresso , no País, de estrangeiros em viagem de turismo Explicação: devendo o estrangeiro adquirir cartão de visitante para viagem de negocio ou de turista).

- PLS 3/2002 de 20/02/2002 Autor: SENADOR - Moreira Mendes Ementa: Acrescenta parágrafo ao artigo 55 da Lei $\mathrm{n}^{\circ}$ 6815, de 19 de agosto de 1980, para permitir a concessão de visto a estrangeiro portador de documento de viagem emitido por governo não reconhecido pelo Governo brasileiro.

PLS 21/2002 de 26/02/2002 Autor: SENADOR - Carlos Wilson Ementa: Altera a redação dos artigos 67 e 89 da Lei ${ }^{\circ}$ 6815, de 19 de agosto de 1980. (Altera o Estatuto do Estrangeiro - dispõe sobre a extradição e julgamento de estrangeiro por delito praticado em solo brasileiro).

PLS 451/2003 de 04/11/2003 Autor: SENADOR - Mozarildo Cavalcanti Ementa: Dispõe sobre o exercício de profissões de saúde por estrangeiros em áreas carentes desses profissionais.

PLS 345/2004 de 25/11/2004 Autor: SENADOR - Mozarildo Cavalcanti Ementa: Dispensa o visto de turistas estrangeiros para visita à Região Amazônica e ao Pantanal. 